\title{
Gerardo Mazzaferro*
}

\section{Commentary: the complex nexus between (im)mobility and translanguaging}

https://doi.org/10.1515/multi-2022-0010

Received January 18, 2022; accepted January 18, 2022; published online February 14, 2022

Abstract: Translanguaging has now become central to a sociolinguistics that foregrounds globalization and mobility as key concepts for grasping human beings' capacity to engage with and draw on both multiple linguistic - including named languages - and semiotic resources dynamically and in combination for the purpose of meaning-making (García, Ofelia \& Wei Li. 2014. Translanguaging: Language, bilingualism and education. New York: Palgrave/McMillan; Li, Wei. 2018. Translanguaging as a practical theory of language. Applied Linguistics 39(1). 9-30). The contributions collected here testify to the growing importance of translanguaging as a theory and practice within contexts of unprecedented mobility, namely educational and work environments, bringing to light processes of circulation of linguistic and semiotic resources across both physical and digital spaces involving the development of communicative practices as well as subjectivities and identities.

Keywords: immobility; mobility; translanguaging

Mobility represents an all-compassing concept for understanding the multiple, fluid and unpredictable construction of the present-day world. It has now become common to observe the complexity of 21st century social realities through the angle of the 'mobilities' perspective concerning spatial and temporal movement of people, material and immaterial goods, cultural, linguistic and semiotic resources across both real and virtual symbolic global spaces (Sheller and Urry 2006; Urry 2007). Some scholars, however, are cautious about enthusiastic and simplifying views of mobility equated with, for example, the 'bidirectional logics of mobility' as movement from place A to place B or the 'nomadic paradigm', celebrating the possibility to navigate the physical world dynamically and incessantly evoking images of autonomous and self-determined subjectivities and identities (Cresswell 2006; Salazar 2011).

Mobility is historically, ideologically, and discursively determined and unequally accessed; in other words, "mobility and control over mobility are both

\footnotetext{
*Corresponding author: Gerardo Mazzaferro, Department of Foreign Languages and Modern Cultures, University of Turin, Via S. Ottavio, 20, 10124 Torino, Italy, E-mail: gerardo.mazzaferro@unito.it
} 


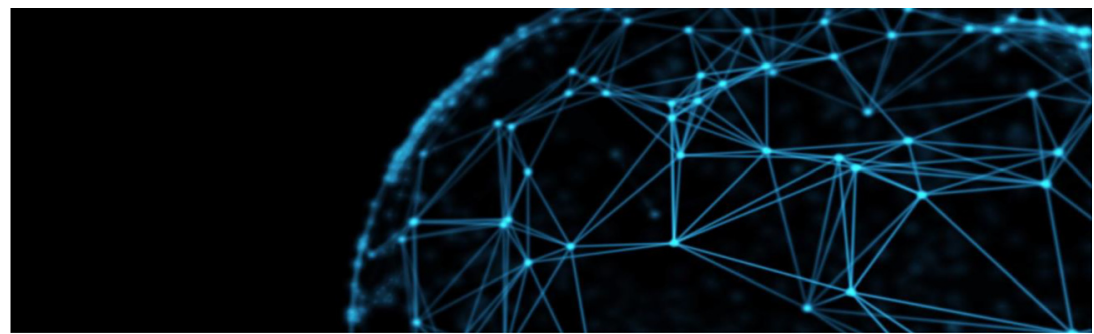

productive of power relations and are produced by them" (Skeggs 2004: 49). We need to pay attention to what Canagarajah (2021: 573) defines as "the dark side of mobility" or the social, cultural, ethnic, religious, gender, economic and political processes constraining people's possibilities, imaginaries, and desires to move. Mobility is linked to forms of (bio)power (Foucault 1977, 1990), which establish, regulate, and discipline mobile individuals such as undocumented migrants and workers, whose mobility is represented as a threat and thus prevented (Adey 2010). Hence, mobility should be put in relation to immobility, that is, mobility and immobility should be seen as two processes, which "go hand in hand" (Canagarajah 2021: 573). The mobility of some people involves the immobility of others (De Fina and Mazzaferro 2021: 120). Undocumented migrants' mobility trajectories, for example, are marked by periods of involuntary and enforced immobility within spaces of detention, control, and governmentality, where migrants are subjected to the "state of exception" (Agamben 2005) or "a separate regime of power that suspends law for an indefinite time” (Fresia and Von Känel 2015: 255), reducing migrants to invisible, voiceless, and non-agentive subjects.

The outbreak of the COVID-19 pandemic, however, has had relevant consequences for human (im)mobility within and beyond current migratory processes. Local, domestic, and global governments have strengthened and imposed policies of enforced immobility to global human populations to respond to the public health situation through immobilizing measures such as lockdown, quarantine and border closures. As clearly stated by Blommaert (2021: 273), the 'normalization' of immobility has become part of 'our social imagination' disrupting and reconfiguring the 'over-celebrations of mobilities'.

As mentioned above, (im)mobility has become a well-established theoretical concern within recent sociolinguistics (De Fina and Mazzaferro 2021) with special attention to the term superdiversity, describing unprecedented cultural, ethnic and linguistic diversity (Vertovec 2007), particularly within Western urban public spaces or "zones of encounters" (Wood and Landry 2007), where forms of conviviality as well as conflict and tension co-exist in everyday social encounters and interactions, 
"[r]ather than working with homogeneity, stability and boundedness as the starting assumptions, mobility, mixing, political dynamics and historical embedding are now central concerns in the study of languages, language groups and communication" (Blommaert and Rampton 2011: 3). However, a new terminology has emerged to index the ways people communicate within and beyond 'superdiverse' contexts. The term translanguaging, among others, has been coined to refer to communication as a creative and critical linguistic and discursive practice, which is transformative of linguistic ideologies, subjectivities, and identities (García and Li 2014; Li 2011, 2018; Mazzaferro 2018).

The contributions in this special issue productively engage with how different types of mobility, power relations and forms of agency challenge the ways language resources, linguistic repertoires and practices are mobilized, circulated, or rejected within and across specific spatio-temporal configurations.

In this issue, Taibi and Badwan explore how new communication and digital technologies increase our understanding of the implications of spatial and temporal or chronotopic configurations (Bakhtin 1981) on how 'wanted mobile individuals', namely international academic sojourners, become 'agentive social actors', who are able to construct 'chronotopic translanguaging practices' by formulating meta-comments about language(s) in use in online communication in order to renegotiate 'past' linguistic norms and ideologies. As made clear by Wang and Kroon "each invocation of timespace also constitutes ascription of specific genres, registers, indexicals and other chronotopically relevant norms, and, as such, enactment of specific intentions, behaviours and effects" (2017: 79). In other words, chronotopes have an impact on situated mobilization and deployment of individuals' language resources, linguistic repertoires, and human agency. The analytical potential of the term chronotope, however, opens up a space for discussion on how translanguaging is not simply and necessarily free, fluid and automatically transformative of space and time, repertoires of resources as well as subjectivities and identities. Hence, following De Fina and Mazzaferro (2021: 166), "TL [translanguaging] and other linguistic practices need to be analyzed within specific contexts and practices". De Fina and Mazzaferro found that, for example, the normative, discursive and ideological configurations of spaces of (im)mobility such as official temporary reception centers for undocumented migrants both constrain the deployment of repertoires of resources that migrants bring with them in mobility and, at the same time, regulate and delegitimize multilingual or translanguaging practices in both institutional and interpersonal communication in order to favour monolingual learning, literacies and ideologies. Within institutionalized migratory contexts, repertoires of resources are accessed and mobilized by necessity in order to impose or resist conditions of immobility. Translanguaging becomes a "heteroglossia of survival” (Busch 2016): that is, a potential transformative practice 
though which migrants can (re)negotiate and challenge power relations and hierarchical positions by developing specific forms of human agency and identity enactments (De Fina and Mazzaferro 2021: 126).

Space and time, thus, are not neutral or void of power, but rather they are shaped and inscribed into webs of power, hierarchical relations, and ideologies (Blommaert and Dong 2010: 8). In their analysis of professional multilingual interactions between temporary mobile workers and local professionals at different construction sites in Sweden, Kahlin, Keevallik, Söderlundh and Weidner (this issue) demonstrate that local social status and hierarchical positions of participants in the interactions are key to the construction of professional spaces through the fluid and creative mobilization of linguistic repertoires of resources including, for example, 'professional key terms' in the local language (Swedish) and English as a lingua franca in the same interaction. Linguistic practices within professional spaces, thus, are strictly linked to both social actors' language awareness and capacity to assign specific values to determined linguistic repertoires of resources, which are subject to 'orders of indexicality'; that is, they acquire new indexical meaning according to context and participants in the interaction (Blommaert 2010: 38).

In learning environments, the possibility to access and mobilize repertoires of resources is instead often disciplined and regulated by official policies and practices as well as individual language attitudes and linguistic ideologies, as seen in the four papers in this issue from the educational context. Norlund Shaswar makes a convincing case that within multilingual educational spaces, teachers' behaviours, attitudes, and ideologies are relevant in the planning of translanguaging as a pedagogical strategy, which aims to develop language awareness and metalinguistic awareness as well as to enhance language and content competences (Cenoz and Gorter 2021). In her study of translanguaging in SFI (Swedish for immigrants) courses for adults, Norlund Shaswar provides insights in how students' access to 'full linguistic repertoires' is unequally distributed and reproduced in line with teacher's orientation towards monolingual norms or 'Swedish only' policies in classroom interactions. In another study of adult learners, Duarte and Günther-van der Meij address the issue of translanguaging as a scaffolding practice supporting learning strategies such as comprehension and translation of words and grammar instruction of prepositions by comparing Dutch to English within a transition program for highly skilled refugees in Dutch higher education. They make evident that translanguaging as an official pre-planned pedagogical practice is constrained by teachers' awareness of norms and linguistic ideologies, namely their 'adherence' to the use of Dutch in classroom interactions, which "rarely enabled students to engage in the joint co-construction of meaning using their full linguistic repertoires and mobile experiences”. 
Wedin explores the interconnections between linguistic and semiotic schoolscapes in a language introduction programme (LIP) in upper secondary school in Sweden and how repertoires of resources are circulated and mobilized within classroom activities and interactions. The author addresses the issue of LIP space as both a closed or ideological space, where assimilation and monolingual, Swedishonly ideologies operate, as well as an implementational space for translanguaging practices including “displayed images, objects, symbols and written language as well as activities, identities and discursive interactions that are indexed and promoted through the schoolscape at this educational site". Along similar lines of thought, Carbonara provides an in-depth account of translanguaging as a pedagogical practice in a public preschool situated in a small village in North-West of Italy. The focus of attention is on translanguaging as a transformative practice which is co-constructed by the interconnections between teachers and children as well as their families both to build awareness-raising of language diversity within and beyond the classroom and to support social justice and transformation. The author clearly demonstrates how a multilingual space or schoolscape is salient to the inclusion and deployment of both children's mobile linguistic repertoires of resources as well as teachers' ability "to prompt translanguaging interaction with children in multiple languages” that is, to construct an inclusive and participatory educational environment.

Each in different ways, all contributions in this issue share a rich ethnographically inspired methodological approach. As has been observed by Heller and colleagues, "[e]thnography is central because it directs our gaze towards social life and its meaning as they unfold in specific times and spaces ... [and] the ability of people who are differently positioned to gain access to key activities and to resources found there" (Heller et al. 2018: 6). The use of ethnography as a method has important implications for a much more in-depth understanding of how translanguaging practices are constructed within and across diverse social and interactional contexts. The papers have shown how translanguaging, unlike for example code-switching or style shift, does not "maintain[s] a perspective on structure as a potential achievement of language and discourse" (Coupland 2007: 50), but rather it refers to both a category of cognition, involving processes of knowledge, comprehension and meaning making as well as an integrated approach to language learning and use, multilingualism and multilingual practices - thus challenging but not denying the divide between named languages and other cognitive systems ( $\mathrm{Li}$ 2016). To conclude, the papers in this issue have opened up a space for the (re)conceptualization of translanguaging at times of unprecedented complexity and mobility. 


\section{References}

Adey, Peter. 2010. Mobility. London, UK and New York, NY: Routledge.

Agamben, Giorgio. 2005. State of exception. Chicago: The University of Chicago Press.

Bakhtin, Mikhail. 1981. The dialogical imagination. Austin: University of Texas Press.

Blommaert, Jan. 2010. The sociolinguistics of globalization. Cambridge: Cambridge University Press.

Blommaert, Jan. 2021. Postscript: Immobilities normalized. In Anna De Fina \& Gerardo Mazzaferro (eds.), Exploring (im)mobilities: Language practices, discourses and imaginaries, 270-273. Bristol: Multilingual Matters.

Blommaert, Jan \& Jie Dong. 2010. Ethnographic fieldwork: A beginner's guide. Bristol: Multilingual Matters.

Blommaert, Jan \& Ben Rampton. 2011. Language and superdiversity. Diversities 13(2). 1-21.

Canagarajah, Suresh. 2021. Rethinking mobility and language: From the Global South. The Modern Language Journal 105(2). 570-582.

Cenoz, Jasone \& Durk Gorter. 2021. Pedagogical translanguaging. Elements in language teaching. Cambridge: Cambridge University Press.

Coupland, Nikolas. 2007. Style: Language variation and identity. Cambridge: Cambridge University Press.

Cresswell, Tim. 2006. On the move. Mobility in the modern western world. London, UK and New York, NY: Routledge.

De Fina, Anna \& Gerardo Mazzaferro. 2021. Everyday communicative practices and repertoires in contexts of involuntary and enforced immobility. In Anna De Fina \& Gerardo Mazzaferro (eds.), Exploring (im)mobilities: Language practices, discourses and imaginaries, 163-182. Bristol: Multilingual Matters.

Fresia, Mariaon \& Andreas Von Känel. 2015. Beyond space of exception? Reflections on the camp through the prism of refugee schools. Journal of Refugee Studies 29(2). 250-272.

Foucault, Michel. 1977. Discipline and punish: The birth of the prison. Translated by Alan Sheridan. London: Allen Lane, Penguin.

Foucault, Michel. 1990. The history of sexuality, Volume 1: An introduction. Translated by Robert Hurley. New York: Vintage.

García, Ofelia \& Li Wei. 2014. Translanguaging: Language, bilingualism and education. New York: Palgrave/McMillan.

Heller, Monica, Sari Pietikäinen, \& Joan Pujolar. 2018. Critical sociolinguistic research methods. Studying language issues that matter. London: Routledge.

Li Wei. 2011. Moment analysis and translanguaging space: Discursive construction of identities by multilingual Chinese youth in Britain. Journal of Pragmatics 43(5). 1222-1235.

Li Wei. 2016. New Chinglish and the post-multilingualism challenge: Translanguaging ELF in China. Journal of English as a Lingua Franca 5(1). 1-26.

Li Wei. 2018. Translanguaging as a practical theory of language. Applied Linguistics 39(1). 9-30.

Mazzaferro, Gerardo. 2018. Translanguaging as everyday practice: An introduction. In Gerardo Mazzaferro (ed.), Translanguaging as everyday practice, 1-12. Cham, Switzerland: Springer.

Salazar, Noel B. 2011. The power of imagination in transnational mobilities. Identities: Global Studies in Power and Culture: Global Studies in Culture and Power 18(6). 576-598. 
Sheller, Mimi \& John Urry. 2006. The new mobilities paradigm. Environment and Planning A: Economy and Space 38(2). 207-226.

Skeggs, Beverley. 2004. Class, self, culture. London: Routledge.

Urry, John. 2007. Mobilities. Cambridge, UK and Malden, MA: Polity Press.

Vertovec, Steven. 2007. Super-diversity and its implications. Ethnic and Racial Studies 30(6). 1024-1054.

Wang, Xuan \& Sjaak Kroon. 2017. The chronotopes of authenticity: Designing the Tujia heritage in China. AlLA Review 30(1). 72-95.

Wood, Phil \& Charles Landry. 2007. The intercultural city: Planning for diversity advantage. London; Sterling, VA: Earthscan. 